Short communication

\title{
TRPC EXPRESSION IN MESENCHYMAL STEM CELLS
}

\author{
FREDERIC TOROSSIAN $^{1,2}$, AURELIE BISSON ${ }^{1}$, JEAN-PIERRE VANNIER ${ }^{2}$, \\ OLIVIER BOYER ${ }^{1}$ and MAREK LAMACZ ${ }^{1, *}$ \\ ${ }^{1}$ Inserm, U905, University of Rouen, IFRMP, Institute for Biomedical Research, \\ Rouen, France, ${ }^{2}$ EA 3829, University of Rouen, Institute for Biomedical \\ Research, Rouen, France
}

\begin{abstract}
Transient receptor potential canonical (TRPC) channels are key players in calcium homeostasis and various regulatory processes in cell biology. Little is currently known about the TRPC subfamily members in mesenchymal stem cells (MSC), where they could play a role in cell proliferation. We report on the presence of TRPC1, 2, 4 and 6 mRNAs in MSC. Western blot and immunofluorescence staining indicate a membrane and intracellular distribution of TRPC1. Furthermore, the decrease in the level of TRPC1 protein caused by RNA interference is accompanied by the downregulation of cell proliferation. These results indicate that MSC express TRPC1, 2, 4 and 6 mRNA and that TRPC1 may play a role in stem cell proliferation.
\end{abstract}

Key words: Mesenchymal stem cells, TRPC1, Cell proliferation

\section{INTRODUCTION}

The identification of several types of stem cells over the past decade has opened interesting possibilities for the development of cellular therapy. Multiples studies have explored crucial cellular functions such as differentiation, proliferation, exocytosis and apoptosis in umbilical cord, embryonic and mesenchymal stem cells [1-4]. These functions are controlled by intracellular calcium-mediated processes. Augmenting the cytosolic calcium concentration occurs through the cooperation of several calcium transporters that mobilize extra- and/or intracellular calcium pools.

* Author for correspondence: Marek Lamacz, Inserm U905, Faculty of Medicine and Pharmacy, 22 bd Gambetta, F-76000 Rouen, France, e-mail: marek.lamacz@univ-rouen.fr, tel.: 33-2-35-14-85-27, fax 33-2-32-88-81-86

Abbreviations used: MSC - Mesenchymal stem cells, TRP - Transient receptor potential, TRPC - Transient receptor potential canonical 
The transient receptor potential (TRP) channels are a superfamily of ionic channels with at least 33 members subdivided into seven subfamilies according to their molecular weight and physiological and physiopathological properties. The canonical subfamily (TRPC) is divided into 4 groups according to sequence similarity $[5,6]$. TRPC 1 and 2 belong to the first and second groups, TRPC3, 6 and 7 form the third, and TRPC4 and 5 are in the fourth. These proteins are composed of 6 transmembrane segments with $\mathrm{N}$ - and C-terminal cytoplasmic regions. The different motifs of these cytoplasmic regions allow the assembly of TRPC subunits to form a heterotetrameric plasma membrane channel or an association with other proteins such as the Orai 1 or IP3 receptors, to which they confer sensitivity during intracellular calcium store depletion [7, 8]. When associated with TRPC4 or 5 [9], TRPC1 may form a functional membrane channel, while the homotetramer appears to be distributed to intracellular compartments.

With the exception of TRPC2, the TRPC proteins were shown to be expressed in a large variety of tissues [for review, see 10], but the different levels of their expression may suggest distinct functions [11]. A notably high level of TRPC1 was detected in the myocytes, neurons and adenohypophyseal cells [11]. High levels of TRPC 3 and TRPC7 are found in the pituitary gland, and of TRPC4 in the bone. TRPC5 is preferentially present in the central nervous system, and TRPC6 appears to be more ubiquitously distributed [11]. Interestingly, the production of TRPC2 seems to be limited to the vomeronasal organ and testis $[12,13]$. There is growing interest in TRPC channels in adult stem cells and other cells with high proliferative and differentiation capacities. For instance, the expression of TRPC1 was recently demonstrated in primary umbilical cord blood CD $34^{+}$cells [14] and in the $\mathrm{C} 2 \mathrm{C} 12$ myoblast line, where it is involved in the initial phase of differentiation [15]. However, little is known about the expression of the TRPC subfamily members in mesenchymal stem cells (MSC) possessing high proliferative and differentiation potentials. Here, we provide the first proof that some TRPC family members are expressed in MSC and that they may further play a role in stem cell proliferation.

\section{MATERIALS AND METHODS}

\section{Cell culture}

Bone marrow was collected from New Zealand white rabbit (Charles River, Chatillon-sur- Chalaronne, France) according to the recommendations of the Consultative French Ethical Committee. Bone marrow mononuclear cells were isolated via Ficoll density gradient centrifugation (Eurobio, Les Ulis, France). MSCs were separated from the CD45 $5^{+}$fraction using a mouse anti-rabbit CD45 antibody (Serotec, Cergy Saint Christophe, France) magnetically labelled with rat anti-mouse IgG1 microbeads (MACS, Miltenyi Biotec $\mathrm{GmbH}$, Bergisch Gladbach, Germany). The separated cells were $99 \%$ CD $45^{-}$, as previously found with other protocols [16]. $6 \times 10^{6} \mathrm{CD} 45^{-}$cells were seeded in four-well 
microplates in a previously described expansion medium [16] containing $60 \%$ low glucose-DMEM (Eurobio), 40\% MCDB-201 (Eurobio), insulin-transferrinselenium supplement (1:100; Invitrogen, Cergy Pontoise, France), 1\% bovine serum albumin (Sigma, Saint Quentin Fallavier, France), $10^{-9} \mathrm{M}$ dexamethasone (Merck, Fontenay-sous-Bois, France), $10^{-4} \mathrm{M}$ ascorbic acid-2-phosphate (Sigma), $10 \mathrm{ng} / \mathrm{ml}$ endothelial growth factor (Euromedex, Souffelweyersheim, France), $10 \mathrm{ng} / \mathrm{ml}$ leukemia inhibitory factor (Euromedex), $10 \mathrm{ng} / \mathrm{ml}$ plateletderived growth factor (Peprotech, Neuilly-Sur-Seine, France), $2 \%$ fetal calf serum (Eurobio), $100 \mathrm{U} / \mathrm{ml}$ penicillin (Sarbach, Suresnes, France) and $100 \mu \mathrm{g} / \mathrm{ml}$ streptomycin (Diamant, Puteaux, France). The cells were cultured in a humidified atmosphere at $5 \% \mathrm{CO}_{2}$ and $37^{\circ} \mathrm{C}$. The medium was changed twice a week until $90 \%$ confluence of adherent cells had been achieved. For the subcultivation, the MSCs were detached with $0.05 \%$ Trypsin-EDTA and placed in a $25-\mathrm{cm}^{2}$ tissue culture flask.

\section{Reverse transcriptase-polymerase chain reaction (RT-PCR) analysis}

The total cellular RNA was extracted from subconfluent cultures using Trizol (Invitrogen). The RNA concentration and integrity were analyzed using an Agilent RNA 6000 Nano LabChip kit with an Agilent 2100 Bioanalyzer (Agilent Technologies, Massy, France). Reverse transcription (Invitrogen), and the polymerase chain reaction (Thermo Scientific, France) was performed according to the manufacturer's instructions.

The primers for TRPC1, 3 and 4 were described by Lee et al. [17], for TRPC2 by Chu et al. [18] and for TRPC6 by Yu et al. [19]. The others primers were defined using the Primer Selection Tool program (Biotools site, University of Massachusetts Medical School, USA) and were: 5'-CTA TGA GAC CAG AGC TAT CGA TG-3' and 5'-CCA CCA GGG AGA TGA CAT TGT ATG-3' for TRPC5; and 5'-GAG AAG GAG AAG CTG GAG CA-3' and 5'-AGA GAA CCC CCA GGG TGA G-3' for OCT-4. The primer-annealing step was realized at $55^{\circ} \mathrm{C}$ for TRPC 1,4 and 6 , and at $54-64^{\circ} \mathrm{C}$ for TRPC2, 3 and 5 according to the touchdown protocol, or at $60^{\circ} \mathrm{C}$ for OCT-4.

\section{Transfection of siRNA}

TRPC1 short interfering RNA (siRNA; Eurogentec, Angers, France) was used: (1) GCC CAC CUG UAA GAA GAU ATT and (2) UAU CUU CUU ACA GGU GGG CTT. A sequence without homology with any known gene (scramble siRNA) was used as a control. siRNA was bound with INTERFERin $^{\mathrm{TM}}$ (Ozyme, Saint Quentin Yvelines, France) into L-DMEM (Eurobio) for $10 \mathrm{~min}$ at room temperature, and applied to the MSC culture, where a fresh prewarmed expansion medium without antibiotics was added. The final concentration of the TRPC1 siRNA (Eurogentec) and scramble siRNA was 100 or $150 \mathrm{nM}$. After $24 \mathrm{~h}$ of incubation, the transfection medium was removed and the MSCs were incubated for another $24 \mathrm{~h}$ in the expansion medium. 


\section{Western blot}

Control and post-transfection MSCs were cultured in the expansion medium with 100 or $150 \mathrm{nM}$ TRPC1 siRNA (Eurogentec) or with $150 \mathrm{nM}$ scramble siRNA. For the protein extraction, 5 million cells were placed in a lysis buffer composed of $100 \mathrm{mM}$ TrisHCl at $\mathrm{pH} 8$, to which a protease inhibitor cocktail containing antipain, calpain inhibitor I and II, chymostatin, TLCK and trypsininhibitor (cOmplete Mini, Roche Diagnostics, USA) was added. A buffer adjusted to $\mathrm{pH} 7.4$ composed of $0.36 \mathrm{M}$ sucrose and $14 \mathrm{mM}$ Hepes was also added. The lysates were clarified by centrifugation for $15 \mathrm{~min}$ at $3,000 \mathrm{~g}$ and $4^{\circ} \mathrm{C}$. The supernatant was centrifuged again for $30 \mathrm{~min}$ at $50,000 \mathrm{~g}$ and $4^{\circ} \mathrm{C}$. The supernatant containing the proteins was stocked at $-80^{\circ} \mathrm{C}$. For the membrane protein extraction, the pellet was incubated in buffer composed of TrisHCl $50 \mathrm{mM}, \mathrm{NaCl} 150 \mathrm{mM}$, EDTA $5 \mathrm{mM}$, KI $1 \mathrm{M}$ and TritonX100 1\%, and the $\mathrm{pH}$ was adjusted to 7.5 and centrifuged at $145,000 \mathrm{~g}$ for $1 \mathrm{~h}$ at $4^{\circ} \mathrm{C}$. The protein concentration was determined using the Bradford method.

Western blots were performed using the XCell II system (Invitrogen) according to the manufacturer's instructions. The goat anti-TRPC1 antibody (Cliniscience, Montrouge, France) was used at a 1:200 dilution and the universal immunoperoxidase polymer anti-goat antibody (Nichirei Biosciences, Tokyo, Japon) was used at a 1:2000 dilution. Antibody binding was revealed using the enhanced chemiluminescence system (Amersham, GE Healthcare, Orsay, France). The densities of the blot bands, expressed in arbitrary units, were obtained using Image Processing and Analysis in Java (ImageJ, NIH Public domain).

\section{Test of MSC proliferation}

Transfected cells were seeded at a density of 25,000 per well in a microplate in the expansion medium described above. Simultaneously, a standard range corresponding to $25,000,50,000,100,000,150,000,200,000$ and 400,000 nontransfected cells per well was prepared. After $24 \mathrm{~h}$ of incubation in a humidified atmosphere at $5 \% \mathrm{CO}_{2}$ and $37^{\circ} \mathrm{C}$, the standard range cells were fixed in acetic alcohol $\left(95 \%\right.$ absolute ethanol, $2 \%$ acetic acid, $\left.3 \% \mathrm{H}_{2} \mathrm{O}\right)$ whereas the TRPC1 siRNA (Eurogentec) or scramble siRNA was transfected into the other cells. After $24 \mathrm{~h}$ of incubation, the transfection medium was removed, and the cells were incubated for another $24 \mathrm{~h}$ in the expansion medium and fixed in acetic alcohol. The standard range and transfected cells were stained with Crystal Violet for $30 \mathrm{~min}$, rinsed with $\mathrm{dH}_{2} \mathrm{O}$, dried for $1 \mathrm{~h}$, and then extracted with $1 \mathrm{ml}$ of $10 \%$ acetic acid. The optical density of the extracts was evaluated using spectrophotometric measurement at $570 \mathrm{~nm}$ (Biotech's Power Wave X Microplate Spectrophotometer, Biotech Instruments, Fisher Scientific). The relative effect of the TRPC1 siRNA (Eurogentec) on cell proliferation was evaluated in comparison to cells transfected with scramble siRNA. The data was compared using Student's $t$-test. 


\section{Immunofluorescence assay}

After $24 \mathrm{~h}$ of incubation in the expansion medium, the MSCs were fixed in a $4 \%$ paraformaldehyde solution, rinsed 3 times with PBS and incubated in a blocking buffer composed of PBS, $0.1 \%$ Tween and 5\% milk for $45 \mathrm{~min}$ at room temperature. Then the cells were incubated with a goat anti-TRPC1 antibody (1:50, Cliniscience) overnight at $4^{\circ} \mathrm{C}$. After the cells had been rinsed 3 times with PBS, a donkey anti-goat secondary antibody conjugated to Alexa Fluor 594 (1:100, Invitrogen) was added for $1.5 \mathrm{~h}$ at room temperature. The nuclei were stained with Hoechst solution (1:5000, Sigma) for $15 \mathrm{~min}$ at room temperature. After washing in PBS, the cells were observed with a Leica DMI6000B fluorescence microscope with a Leica CTR 6000 light source.

\section{RESULTS AND DISCUSSION}

There is a lack of knowledge about TRPC channel expression in bone marrow MSC, so RT-PCR was used to determine which types of channel are expressed in these cells. To be sure of having immature MSC to work with, we demonstrated their ability to express the OCT-4 gene, a recognized marker of stem cell immaturity [20]. It is represented in Fig. 1A by a 231-bp apparent band obtained via RT-PCR analysis. In a more selective way, the studied cells showed the capacity to differentiate into osteoblasts, chondrocytes and adipocytes, characterized by distinct features like calcium phosphate, glycosaminoglycans and lipids, demonstrating their mesenchymal origin (data not shown).

The analysis of the TRPC family expression evidenced that the MSC mobilize the TRPC1, 2, 4 and 6 genes (Fig. 1B, image 1). For TRPC4, we detected mRNA with a slightly greater size than expected, but it was absent from the rabbit brain extracts (Fig. 1B image 2) used as a classical positive control for the expression of all the regular TRPC family members [10]. This observation suggests that MSC may express an already described splice variant [21]. In the same way, for TRPC2, the weak band of higher weight may correspond to the cDNA of TRPC2A, identified as spliced form of TRPC2 [22, 23].

Since the TRPC1 protein plays a role in important functions such as proliferation, contraction, differentiation or secretion in a large variety of normal and pathological cells [for a review, see 10, see also 24], we chose to analyse its cellular localization in the MSC and sought a possible role for it in cell proliferation. Using Western blot, we were able to detect the presence of an approximately $49-\mathrm{kDa}$ TRPC1 protein band in both the cytosolic and membrane fractions (Fig. 1C). While this molecular weight does not correspond to the generally reported values of around $100 \mathrm{kDa}$ [25], it is close to the isoform of TRPC1 detected in rat neurons [26]. Indeed, a short isoform has already been 


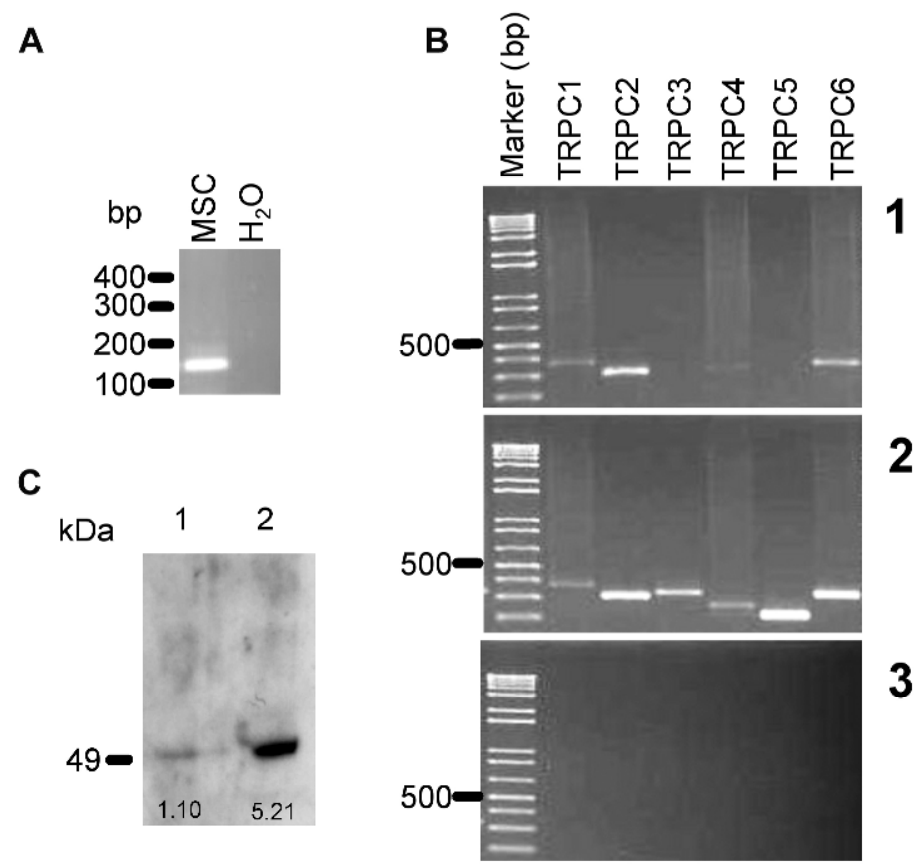

Fig. 1. The identification of OCT-4 and TRPC1, 2, 4 and 6 in rabbit bone marrow mesenchymal stem cells (MSC). A - The amplification of a 151-bp band corresponding to OCT-4 mRNA in the MSC. Distilled water was used as a control. B - TRPC1, 2, 3, 4, 5 and $6(372,310,331,265,220$ and $327 \mathrm{bp}$, respectively) were analyzed in the MSC (image 1) and in rabbit brain tissue (image 2). Distilled water was used as a control (image 3). $\mathrm{C}-\mathrm{A}$ western blot analysis of the TRPC1 protein in a membrane (lane 1) and cytosol extract (lane 2) of MSC containing $10 \mu \mathrm{g}$ of proteins per lane. The apparent molecular weight of the TRPC1 protein is $49 \mathrm{kDa}$. The densities of blot bands, expressed in arbitrary units, are indicated below the bands.

detected via RT-PCR in salivary gland cells [27] or in immature CD34 $4^{+}$cells [14] and shown to disappear and be progressively replaced by the unspliced TRPC1 form during that differentiation into megacaryocytes [14]. Further immunofluorescence staining corroborated these results by showing that a large majority of MSC express TRPC1 (Fig. 2A). The most intense staining (Fig. 2B) appeared as a large juxtanuclear network suggesting an endoplasmic reticulum (ER) localization of TRPC1, as previously reported by Alfonso et al. [9]. Interestingly, rare cells, marked by a very luminous perinuclear halo ( $>1.4$ arbitrary units in comparison to $<0.22$ for others), seemed to produce a higher quantity of TRPC1. Notably, a high expression of this protein in human myoblasts was observed during the initial stage of differentiation and its diminution coincided with an increase in the T-type voltage-dependent calcium channel expression essential for myotube formation [15]. In dividing cells, TRPC1 staining appeared as a densely spun web formation displaced to the border zone of division and as peripheral luminous spots suggesting a membrane 

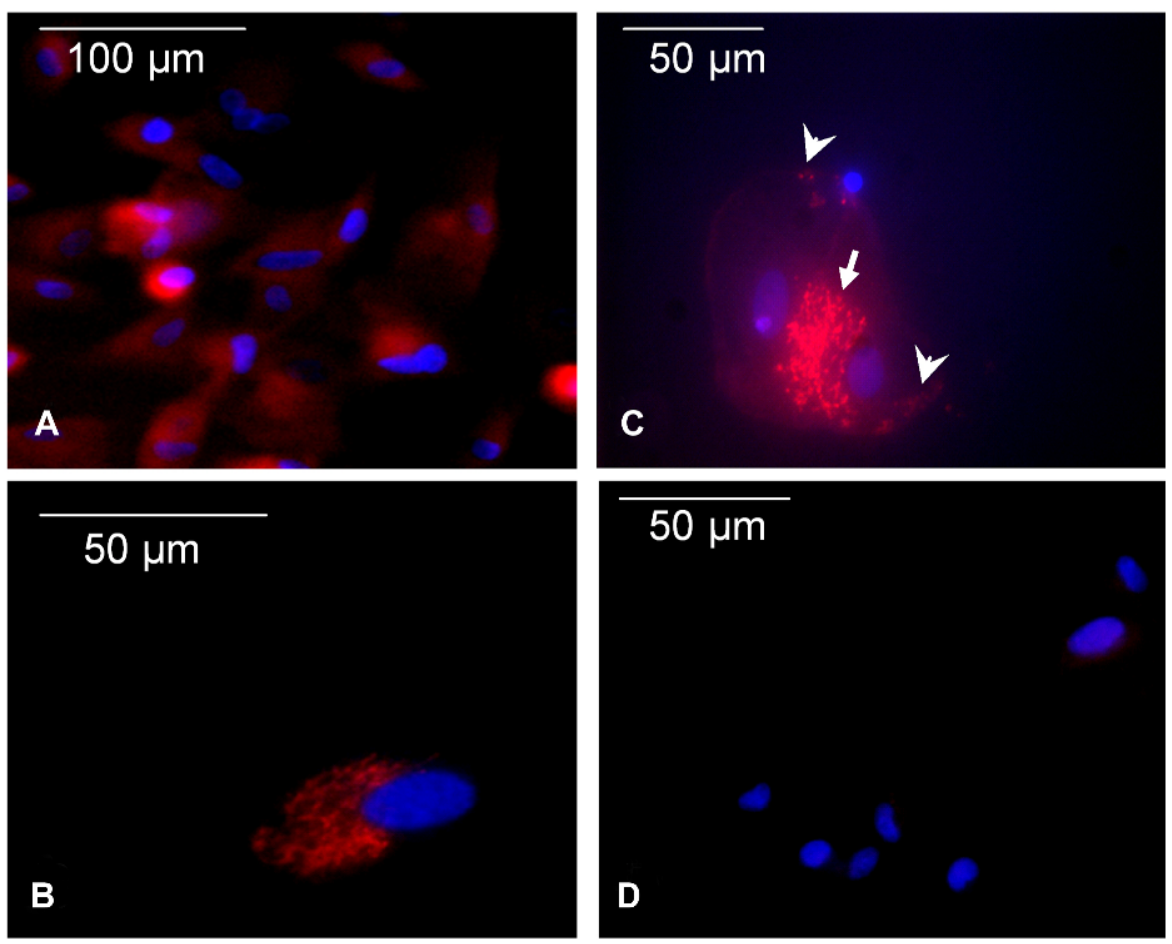

Fig. 2. The localization of TRPC1 in bone marrow mesenchymal stem cells (MSC) assessed via anti-TRPC1 immuno-fluorescence. A-B - TRPC1 staining of resting MSC at low and high magnification. C - Localization of TRPC1 staining at the intracellular interface of dividing cells (arrow). The arrowhead indicates dispersed membrane-like material. D - Staining with a secondary antibody in the absence of the anti-TRPC1 antibody was used as a negative control. Nuclei stained with Hoechst.

localization (Fig. 2C, arrows). It should be noted that the convergent Western blot results indicated the presence of the TRPC1 protein in the membrane and the cytosolic fractions. Such a membrane and intracellular distribution of TRPC1 already reported for the other types of differentiated and non-differentiated cells supported our observation [9]. It is admitted that the TRPC membrane channels represent heterotetramers where TRPC1 may be associated with other TRPC proteins, such as TRPC4 and TRPC5 [9], which is not found in MSC, or with TRPC6, which is detected on the membrane of mesangial cells [28]. In addition, the joint expression of the TRPC1 and TRPC6 proteins was identified in pulmonary vascular smooth muscle cells [19] and human hepatoma cells [29]. The expression of TRPC2 and TRPC6 in the MSC and the preponderant distribution of TRPC1 in an ER-like space lead us to consider the probability of the formation of TRPC2/TRPC6 heteromultimers, as described for the membrane of primary erythroid cells $[8,23]$ and homotetramers coupled to an IP3 cascade as observed in HEK293 cells [9] or DT40 B lymphocytes [30]. 
Further immunocytochemical studies of protein distribution and evaluation of microfluorimetric calcium fluxes should give an exact demonstration of the role of the detected TRPC proteins in the MSC, especially as the same protein may be addressed to the plasma membrane and to the ER [8, 23]. Given the weak documentation concerning the peripheral tissue distribution of TRPC2, revealing its expression and role in the MSC is particularly interesting. Since no specific pharmacological TRPC1 blockers are available to date, we inactivated the production of this protein by RNA interference in order to evaluate its effect on cell proliferation. In comparison to scramble siRNA, the intensity of the TRPC1 apparent band was significantly decreased, indicating a dose-dependent inhibition of TRPC1 expression by specific siRNA used at concentrations of 100 $\mathrm{nM}$ (Fig. 3A, lane 3; $\mathrm{p}<0.02$ ) and $150 \mathrm{nM}$ (Fig. 3A, lane 4; $<<0.01$ ). Consequently, this reduction in TRPC1 gene expression was accompanied by a significant downregulation of MSC proliferation (Fig. 3B), corresponding to a $42 \%$ diminution in comparison to the scramble $(\mathrm{p}<0.05)$.

\section{A}
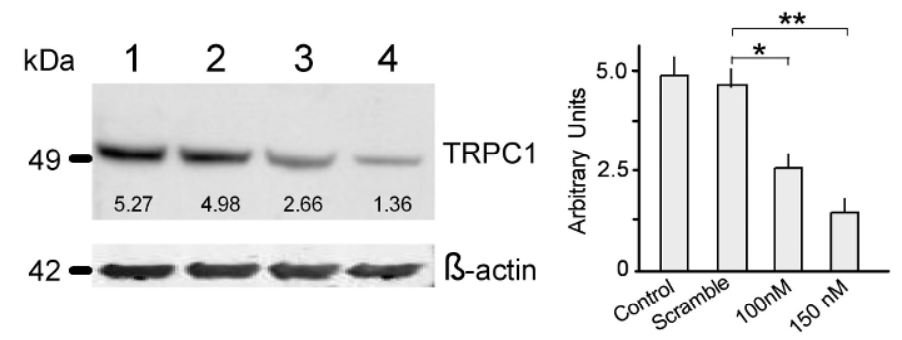

B

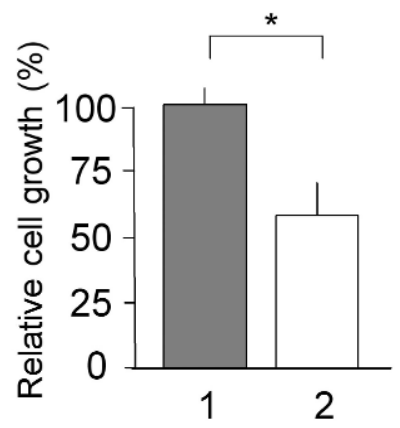

Fig. 3. The functional role of TRPC1 in rabbit bone marrow mesenchymal stem cells (MSC). A - Western blot detected an inhibition of TRPC1 expression in the MSC by TRPC1-specific siRNA (100 nM, lane 3; $150 \mathrm{nM}$, lane 4) in comparison with controls representing non-transfected MSC (lane 1) and MSC transfected with scramble siRNA $(150 \mathrm{nM}$, lane 2). Each lane contains $10 \mu \mathrm{g}$ of proteins from total lysate. The densities of the blot bands, expressed in arbitrary units, are indicated below the bands. B - The inhibition of the proliferation of MSC transfected with scramble (100 nM, histogram 1) or TRPC1 siRNA (100 nM, histogram 2).

Our results for MSC indicate that the TRPC1 protein also plays an important role in the proliferation of stem cells, in accordance with recent results for breast cancer cells [31] and osteoblasts [32]. It should be noted that the hepatoma cell 
proliferation depended on the expression of the TRPC6 gene but not on that of the TRPC1 gene [29], indicating the necessity of a detailed study of the localization and functionality of the two proteins in the MSC.

Our data suggests that: i) the MSC express genes encoding TRPC1, 2, 4 and 6; ii) the TRPC1 protein is present in both the membrane and cytosolic fractions of the MSC; and iii) TRPC1 plays an important role in the proliferation of MSC.

Acknowledgements. Frederic Torossian is a recipient of a fellowship from the Conseil Régional de Haute-Normandie (France). This study was supported in part by grants from the Associations "TI'TOINE" and "Vie et Espoir". We would like to thank Manuel Freret for his help with the Western blot study. We are grateful to Dr. Serge Jacquot for his critical reading of this article.

\section{REFERENCES}

1. Lepski, G., Jannes, C.E., Maciaczyk, J., Papazoglou, A., Mehlhorn, A.T., Kaiser, S., Teixeira, M.J., Marie, S.K., Bischofberger, J. and Nikkhah, G. Limited $\mathrm{Ca} 2+$ and PKA-pathway dependent neurogenic differentiation of human adult mesenchymal stem cells as compared to fetal neuronal stem cells. Exp. Cell Res. $\underline{316}$ (2010) 216-231.

2. Meldolesi, J. Inhibition of adipogenesis: a new job for the ER $\mathrm{Ca} 2+$ pool. J. Cell Biol. 182 (2008) 11-13.

3. Wang, L., Singh, M., Bonewald, L.F. and Detamore, M.S. Signalling strategies for osteogenic differentiation of human umbilical cord mesenchymal stromal cells for 3D bone tissue engineering. J. Tissue Eng. Regen. Med. $\underline{3}$ (2009) 398-404.

4. Ng, K.M., Lee, Y.K., Chan, Y.C., Lai, W.H., Fung, M.L., Li, R.A., Siu, C.W. and Tse, H.F. Exogenous expression of HIF-1 alpha promotes cardiac differentiation of embryonic stem cells. J. Mol. Cell. Cardiol. $\underline{48}$ (2010) 1129-1137.

5. Lepage, P.K., Lussier, M.P., McDuff, F.O., Lavigne, P. and Boulay, G. The self-association of two N-terminal interaction domains plays an important role in the tetramerization of TRPC4. Cell Calcium $\underline{45}$ (2009) 251-259.

6. Clapham, D.E., Julius, D., Montell, C. and Schultz, G. International Union of Pharmacology. XLIX. Nomenclature and structure-function relationships of transient receptor potential channels. Pharmacol. Rev. 57 (2005) 427-450.

7. Ong, H.L., Cheng, K.T., Liu, X., Bandyopadhyay, B.C., Paria, B.C., Soboloff, J., Pani, B., Gwack, Y., Srikanth, S., Singh, B.B., Gill, D.L. and Ambudkar, I.S. Dynamic assembly of TRPC1-STIM1-Orai1 ternary complex is involved in store-operated calcium influx. Evidence for similarities in store-operated and calcium release-activated calcium channel components. J. Biol. Chem. 282 (2007) 9105-9116.

8. Tong, Q., Chu, X., Cheung, J.Y., Conrad, K., Stahl, R., Barber, D.L., Mignery, G. and Miller, B.A. Erythropoietin-modulated calcium influx 
through TRPC2 is mediated by phospholipase Cgamma and IP3R. Am. J. Physiol. Cell Physiol. 287 (2004) C1667-1678.

9. Alfonso, S., Benito, O., Alicia, S., Angelica, Z., Patricia, G., Diana, K. and Vaca, L. Regulation of the cellular localization and function of human transient receptor potential channel 1 by other members of the TRPC family. Cell Calcium 43 (2008) 375-387.

10. Abramowitz, J. and Birnbaumer, L. Physiology and pathophysiology of canonical transient receptor potential channels. FASEB J. 23 (2009) 297-328.

11. Riccio, A., Medhurst, A.D., Mattei, C., Kelsell, R.E., Calver, A.R., Randall, A.D., Benham, C.D. and Pangalos, M.N. mRNA distribution analysis of human TRPC family in CNS and peripheral tissues. Brain Res. Mol. Brain Res. 109 (2002) 95-104.

12. Lucas, P., Ukhanov, K., Leinders-Zufall, T. and Zufall, F. A diacylglycerolgated cation channel in vomeronasal neuron dendrites is impaired in TRPC2 mutant mice: mechanism of pheromone transduction. Neuron 40 (2003) 551-561.

13. Stowers, L., Holy, T.E., Meister, M., Dulac, C. and Koentges, G. Loss of sex discrimination and male-male aggression in mice deficient for TRP2. Science 295 (2002) 1493-1500.

14. den Dekker, E., Molin, D.G., Breikers, G., van Oerle, R., Akkerman, J.W., van Eys, G.J. and Heemskerk, J.W. Expression of transient receptor potential mRNA isoforms and $\mathrm{Ca}(2+)$ influx in differentiating human stem cells and platelets. Biochim. Biophys. Acta 1539 (2001) 243-255.

15. Louis, M., Zanou, N., Van Schoor, M. and Gailly, P. TRPC1 regulates skeletal myoblast migration and differentiation. J. Cell Sci. 121 (2008) 3951-3959.

16. Reyes, M., Lund, T., Lenvik, T., Aguiar, D., Koodie, L. and Verfaillie, C.M. Purification and ex vivo expansion of postnatal human marrow mesodermal progenitor cells. Blood 98 (2001) 2615-2625.

17. Lee, C.H., Rahimian, R., Szado, T., Sandhu, J., Poburko, D., Behra, T., Chan, L. and van Breemen, C. Sequential opening of IP(3)-sensitive $\mathrm{Ca}(2+)$ channels and SOC during alpha-adrenergic activation of rabbit vena cava. Am. J. Physiol. Heart Circ. Physiol. 282 (2002) H1768-1777.

18. Chu, X., Cheung, J.Y., Barber, D.L., Birnbaumer, L., Rothblum, L.I., Conrad, K., Abrasonis, V., Chan, Y.M., Stahl, R., Carey, D.J. and Miller, B.A. Erythropoietin modulates calcium influx through TRPC2. J. Biol. Chem. 277 (2002) 34375-34382.

19. Yu, Y., Sweeney, M., Zhang, S., Platoshyn, O., Landsberg, J., Rothman, A. and Yuan, J.X. PDGF stimulates pulmonary vascular smooth muscle cell proliferation by upregulating TRPC6 expression. Am. J. Physiol. Cell Physiol. 284 (2003) C316-330.

20. Niwa, H., Miyazaki, J. and Smith, A.G. Quantitative expression of Oct-3/4 defines differentiation, dedifferentiation or self-renewal of ES cells. Nat. Genet. 24 (2000) 372-376. 
21. Schaefer, M., Plant, T.D., Stresow, N., Albrecht, N. and Schultz, G. Functional differences between TRPC4 splice variants. J. Biol. Chem. 277 (2002) 3752-3759.

22. Hofmann, T., Schaefer, M., Schultz, G. and Gudermann, T. Cloning, expression and subcellular localization of two novel splice variants of mouse transient receptor potential channel 2. Biochem. J. 351 (2000) 115-122.

23. Chu, X., Tong, Q., Cheung, J.Y., Wozney, J., Conrad, K., Mazack, V., Zhang, W., Stahl, R., Barber, D.L. and Miller, B.A. Interaction of TRPC2 and TRPC6 in erythropoietin modulation of calcium influx. J. Biol. Chem. 279 (2004) 10514-10522.

24. Ambudkar, I.S., Ong, H.L., Liu, X., Bandyopadhyay, B.C. and Cheng, K.T. TRPC1: the link between functionally distinct store-operated calcium channels. Cell Calcium 42 (2007) 213-223.

25. Chen, J., Crossland, R.F., Noorani, M.M. and Marrelli, S.P. Inhibition of TRPC1/TRPC3 by PKG contributes to NO-mediated vasorelaxation. Am. J. Physiol. Heart Circ. Physiol. 297 (2009) H417-424.

26. Wang, W., O'Connell, B., Dykeman, R., Sakai, T., Delporte, C., Swaim, W., Zhu, X., Birnbaumer, L. and Ambudkar, I.S. Cloning of Trplbeta isoform from rat brain: immunodetection and localization of the endogenous Trp1 protein. Am. J. Physiol. 276 (1999) C969-979.

27. Vag, J., Byrne, E.M., Hughes, D.H., Hoffman, M., Ambudkar, I., Maguire, P. and O'Connell, B.C. Morphological and functional differentiation of HSG cells: role of extracellular matrix and trpc 1. J. Cell Physiol. 212 (2007) 416-423.

28. Sours, S., Du, J., Chu, S., Ding, M., Zhou, X.J. and Ma, R. Expression of canonical transient receptor potential (TRPC) proteins in human glomerular mesangial cells. Am. J. Physiol. Renal Physiol. 290 (2006) F1507-1515.

29. El Boustany, C., Bidaux, G., Enfissi, A., Delcourt, P., Prevarskaya, N. and Capiod, T. Capacitative calcium entry and transient receptor potential canonical 6 expression control human hepatoma cell proliferation. Hepatology 47 (2008) 2068-2077.

30. Mori, Y., Wakamori, M., Miyakawa, T., Hermosura, M., Hara, Y., Nishida, M., Hirose, K., Mizushima, A., Kurosaki, M., Mori, E., Gotoh, K., Okada, T., Fleig, A., Penner, R., Iino, M. and Kurosaki, T. Transient receptor potential 1 regulates capacitative $\mathrm{Ca}(2+)$ entry and $\mathrm{Ca}(2+)$ release from endoplasmic reticulum in B lymphocytes. J. Exp. Med. 195 (2002) 673-681.

31. El Hiani, Y., Ahidouch, A., Lehen'kyi, V., Hague, F., Gouilleux, F., Mentaverri, R., Kamel, S., Lassoued, K., Brule, G. and Ouadid-Ahidouch, H. Extracellular signal-regulated kinases 1 and 2 and TRPC1 channels are required for calcium-sensing receptor-stimulated MCF-7 breast cancer cell proliferation. Cell. Physiol. Biochem. 23 (2009) 335-346.

32. Labelle, D., Jumarie, C. and Moreau, R. Capacitative calcium entry and proliferation of human osteoblast-like MG-63 cells. Cell Prolif. $\underline{40}$ (2007) 866-884. 